\title{
Toward Understanding Inter-organizational Knowledge Transfer Needs in SMEs: Insight from a UK Investigation
}

\author{
Shizhong Chen, Yanqing Duan, John S. Edwards and Brian Lehaney
}

\begin{abstract}
Purpose - External knowledge is generally believed to be of prime importance to SMEs. However, a review of the literature shows that no empirical research has looked at knowledge management issues at the interorganizational level in SMEs. This paper reports on an empirical investigation with UK SMEs in the service sector to identify their needs and practices regarding inter-organizational knowledge transfer, and thus provide empirical evidence to support the above belief.

Design/methodology/approach - A two-tier methodology (i.e. using both questionnaire survey and interview approaches) is deployed to address the main research objectives. A questionnaire survey of SMEs is carried out to investigate their current inter-organizational knowledge transfer situation and managers' perception on various relevant issues. Then twelve face-to-face interviews with SME managers are conducted to further validate key findings drawn from the questionnaire survey.

Findings -The empirical evidence collected from the survey and interviews confirms the general belief that external knowledge is of prime importance for SMEs, and demonstrates that SMEs have very strong needs for external knowledge and inter-organizational knowledge transfer.
\end{abstract}

Research limitations/implications - The findings provide very strong underpinning for further theoretical research on inter-organizational knowledge transfer in SMEs. However, this study has certain limitations: its results may not be applicable to other industrial sectors or the same sector in other countries; or to micro or large companies; nor does it involve cross-cultural issues.

Originality/value - By adopting a two-tier research methodology, this study provides more reliable understanding and knowledge on SMEs' inter-organizational knowledge transfer needs and practices, and fills the gap that exists in the empirical investigations on the subject.

\section{Keywords}

SMEs; Knowledge Management; Knowledge Transfer; Inter-Organization; Survey; Interview.

\section{Introduction}

Knowledge is thought to be the only meaningful resource today. The traditional factors of production have become secondary. It is straightforward to obtain them, provided there is knowledge (Drucker, 1993). Therefore, it is knowledge that is the key to business success. To remain at the forefront and maintain a competitive edge companies must have a good capacity to retain, develop, organise, transfer and utilise their knowledge resources. This requires systematic knowledge management (KM) 
(Wiig, 1997).

SMEs appear increasingly crucial to the success of a national economy (Johnston \& Loader, 2003). For example, at the beginning of 2000 , it was estimated that there were 3.7 million businesses which could be regarded as active in UK, of these, small businesses accounted for over $99 \%$ and a further 25,000 were of medium size (Bradford, 2004); in 2002, SMEs were responsible for about $60 \%$ of China's industrial output and employed about $75 \%$ of the workforce in China's cities and towns (USA, 2002). Beck et al (2004) studied SMEs in 62 countries. In the majority of them the SME share of total employment was well over 50\%, reaching $86 \%$ in Chile, Greece and Thailand. They also found a strong association between the importance of SMEs to the national economy and GDP per capita growth.

Obviously, SMEs' effectiveness in leveraging knowledge will play a key role in the success of a national economy. Effort devoted to study or exploration of KM issues related to SMEs is considered to be worthwhile. However, KM, as an emerging discipline (Ives et al., 1998), is mainly derived from large businesses (Deakins, 1999). As a result, only a small proportion of the literature has attempted to address knowledge management issues in SMEs (Deakins, 1999; Sparrow, 2001), which is not in line with the importance of SMEs in the national economy.

Experience and lessons learned from large businesses can not be directly applied to SMEs, as Sparrow (2001, p.3) argues “... like so many aspects of business and management, the knowledge management issues that SMEs will face may not be simply a scaled-down replica of large company experiences". SMEs may be distinguished from large companies, by some or all of the following features: flexibility and volatility, skill (or expertise) shortages, very limited market power, market behaviours mainly affected by partners or competitors (Deakins, 1999; Duan et al., 2001). Therefore, external knowledge is of prime importance to SMEs, whereas large businesses may pay more attention to the knowledge of their internal aspects (Sparrow, 2001). However, this general belief cannot be accepted without 
further argument. Since this paper is mainly concerned with SMEs, and hence focuses on the issues that are of great relevance to the argument that external knowledge is of prime importance to SMEs (Sparrow, 2001).

Firstly, it is a natural concern whether there is practical evidence to support the argument. Further, in which areas may this conclusion be specifically reflected? The external knowledge for a company actually exists in its business environment, which is defined as 'the relevant physical and social factors outside the boundary of an organization that are taken into consideration during organizational decision-making' (Daft et al., 1988). The environment has two layers. The one closest to the organization is the task environment, with sectors that have direct transactions with the organization, such as competitors, suppliers, and customers. The outer layer represents the general environment and refers to sectors that affect organizations indirectly, such as the economic, legal, social and demographic ones (Xu et al., 2003). Daft et al. (1988) found that sectors in the task environment generate greater strategic uncertainty than those in the general environment, and thus are perceived as more important than the latter. So, this research will focus on the task environment. Xu et al. (2003), through a questionnaire survey, revealed that customers, competitors and market sectors are perceived as most strategically important by UK executives from five industries: computer, food, chemical, electronics and transport. This partially confirms the finding of Daft et al. (1988). However, "the sample selected is medium to larger sized companies, the results may not be applicable to very large or small and entrepreneurship enterprises” (Xu et al., 2003, p.8). Furthermore, “... earlier studies treat the business environment as a single entity" (Xu et al., 2003, p.1). Therefore, it seems worthwhile to attempt to divide the task environment into sectors and identify SMEs' perception of the importance of knowledge in these sectors.

Secondly, the knowledge in identified sectors of the task environment will be finally related to particular organizations, e.g. the market sector identified by Xu et al. (2003) is related to customers, suppliers or competitors. So, once the importance of external knowledge in the relevant sectors of the task environment for SMEs is identified, it may be considered whether SMEs have sufficient 
knowledge about the organizations related to the identified sectors. Obviously, if SMEs have been aware of their insufficiencies in knowledge about the relevant organizations, i.e. knowledge gaps about these organizations exist in them, they will need to acquire the external knowledge through learning from the these organizations, i.e. through inter-organizational knowledge transfer (Szulanski, 2000; Beijerse, 2000; Chen et al., 2003). Therefore, SMEs' needs for inter-organizational knowledge transfer can be identified by means of the identification of their knowledge insufficiencies about the relevant organizations.

Thirdly, to acquire external knowledge, SMEs need to engage in some activities to interact with external organizations, i.e. inter-organizational knowledge transfer activities. Obviously, if SMEs have no need for inter-organizational knowledge transfer, they will have no motivation to take part in knowledge transfer activities. So, the identification of these activities may reflect SMEs' needs for inter-organizational knowledge transfer from another perspective, and also demonstrate their current practices in the area. Beijerse (2000) identifies 79 instruments with which knowledge is organised in SMEs, of which 5 reflect inter-organizational knowledge transfer activities. Knowledge transfer is thought of as an important part of KM (Davenport and Prusak, 1998; Nissen et al., 2000; Beijerse, 2000). A review (Chauvel and Despres, 2002) of various KM surveys conducted between 1997 and 2001 shows that these surveys were designed to investigate KM issues from six dichotomous dimensions, i.e. phenomena, action, level, knowledge, technology and outcomes. In the level dimension, the surveys have typically focused on $\mathrm{KM}$ at the individual, divisional and organizational levels. Very few surveys have been designed to look at KM issues at the inter-organizational level in SMEs. KM issues related to SMEs have tended to be ignored, especially at the inter-organizational level. The identification of SMEs' current practices and needs for inter-organizational knowledge transfer will contribute knowledge to this area.

Fourthly, organizations need channels to facilitate their knowledge exchange in the interorganizational knowledge transfer activities. Social and electronic networks are thought of as being two such channels (Chen et al., 2002). The social network may provide opportunities for face-to-face 
communication, produce strong ties between member organizations through the appropriate application of the two mechanisms - trust and power, and thus work as a channel to transfer both tacit and explicit knowledge between member organizations (Dyer and Nobeoka, 2000; Chen et al., 2002). An electronic network may work as another channel to transfer knowledge between organizations (Chen et al., 2002). Although there are some difficulties for an electronic network to transfer tacit knowledge, it has advantages over social networks in rapidly transferring explicit knowledge, rapidly developing weak ties and greatly reducing communication cost (Grandori and Soda, 1995; Preece, 2000; Jones and Beckinsale, 2001; Warkentin et al., 2001). So, the member organizations of a social network may build up their own electronic network to facilitate explicit knowledge transfer between them. Even if this case has not happened in a social network, its member organizations may still use network technology such as the Internet to market products or acquire knowledge from external sources (Chen et al., 2002). Therefore, the current situation and effectiveness of SMEs' use of both social and electronic networks to facilitate knowledge exchange between organizations need to be examined.

Finally, inter-organizational knowledge transfer is actually the process of organizations learning from each other. This inter-organizational learning may be considered as being composed of two subprocesses: 1) inter-individual learning between individuals from different organizations; 2) once the individual recipient has acquired the needed knowledge, the conversion of individual learning into organizational learning through organizational internal mechanisms (Chen et al., 2002). From the organizational learning perspective, a criterion for success is that, knowledge that is received by individuals from external sources, should be communicated and utilised effectively throughout the organization so that its business is improved (Argyris \& Schon, 1996; Dodgson, 1993; Beeby and Booth, 2000). Szulanski (2000) also argues that a successful knowledge transfer for an organization should improve its business performance. So, the effectiveness of SMEs' inter-organizational knowledge transfer is also a matter of concern and will be measured on whether the acquired external knowledge is effectively used by SMEs to improve their businesses. 


\section{Research objectives and methods}

The research reported in this paper sought to examine these issues for SMEs in the context of the UK service sector. Specifically, it is designed to identify:

- The importance of external knowledge to SMEs.

- SMEs' needs for inter-organizational knowledge transfer.

- SMEs' actual situation in the involvement of the relevant knowledge transfer activities.

- SMEs' perception on the importance of social and electronic networks in helping them to acquire the necessary external knowledge, and their actual effectiveness in using social and electronic networks to do so.

- SMEs' effectiveness in using the acquired external knowledge to improve their business performance.

A two-tier methodology (i.e., using both survey and interview approaches) was deployed to address the main research objectives. This mixed method approach has been adopted by a number of researchers in their studies with SMEs (e.g. Barry and Milner 2002; Lawson et al., 2003; Ramsey et $a l ., 2003)$. By using both survey and interview approaches, it is anticipated that more reliable and validated findings can be obtained.

\section{Administration of the survey}

\section{Questionnaire design}

The existing KM literature offers several examples of questionnaire surveys (or assessments) for companies. For instance, a questionnaire survey (Chase, 1997) jointly sponsored by the Journal of Knowledge Management, the Best Practice Club, and the Benchmarking Exchange, contains 18 questions covering knowledge creation, knowledge management lever and technology in large companies. An on-line assessment (UCE, 2001) of knowledge management, designed by University of Central England, seeks to measure companies' abilities to manage knowledge from the perspectives of knowledge-in-use, knowledge systems, knowledge renewal, and 'knowledge 
economy' management capability. Beijerse (2000) identifies 79 instruments with which knowledge is organised in SMEs, of which 20 are for knowledge sharing, but mainly at an operational level. None of these could be directly used for an inter-organizational knowledge transfer survey for SMEs in the context of this research. However, some of the previous survey questions can be used in this survey.

The questionnaire developed for this research includes 14 questions.

- Question 1 aims to measure the size of companies.

- Question 2 (containing 8 sub-questions) is taken from Chase (1997), and amended to reflect the importance of external knowledge. Because the task environment (e.g., customers, suppliers, competitors or other organizations) is perceived to be more important than the general environment for companies (Daft et al., 1988), so the external knowledge related to the general environment is excluded by this question. Further, some important internal knowledge (e.g., own competencies/capabilities, own products/services) for a company is covered by this question. Then, the comparative judgement on the importance of both the task environment and the internal knowledge can be collected from the respondents. If the results demonstrate that the external knowledge is perceived by respondents to be more important than the internal knowledge for SMEs. This will strongly support the belief that external knowledge is of prime importance to SMEs (Sparrow, 2001). Otherwise, the belief will be wrong.

- Question 3 (containing 6 sub-questions) is also taken from Chase (1997), and amended to reflect SMEs' sufficiency in the external knowledge identified by question 2. If the insufficiencies are perceived by respondents to exist in SMEs, they will have needs to acquire the external knowledge from the relevant organizations. Otherwise, they may have no need to acquire the external knowledge.

- Question 4 (containing 11 sub-questions) aims to identify the actual situation of SMEs' involvement in, or their needs for, inter-organizational knowledge transfer activities. Six of the 11 sub-questions are taken from Beijerse (2000) and UCE (2001), 3 from each.

- Questions 5-12 aim to identify the actual situation of SMEs' involvement in social networks and electronic networks, collect information about the proportion of social networks which have their 
own electronic networks, and assess the importance and the actual effectiveness of both social and electronic networks in helping SMEs to acquire the necessary external knowledge.

- Question 13, taken from Chase (1997), aims to assess SMEs' effectiveness in using the acquired external knowledge to improve their business performance.

- Question 14 aims to identify the respondents' positions in their companies.

Three questions (questions 2, 7 and 13) use a 5-point scale ranging from "1" (very ineffective or unimportant) to "5" (very effective or important), two questions (questions 5 and 6) are open-ended questions, the others are two- (i.e., yes or no) or multiple-option questions. All of them are designed to be as short and simple as possible, so that they are easy to understand and answer by the respondents.

The survey is descriptive, not exploratory, in nature and mainly examines the perceptions of respondents on the above issues. Although perceptual data has deficiencies, Duan and Kinman (2000) argue that there is a strong degree of convergence between the two measurement methods (perceptual vs behavioural), and perceptual measurement should still yield valuable information.

\section{Sampling}

The working definition of SMEs this research adopts is the EU definition, i.e., companies that have between 10 and 249 employees (Deakins, 1999). All SMEs in the UK service sector were extracted from the Financial Analysis Made Easy (FAME) database. From these, 1,000 SMEs were randomly selected as the sample for the survey.

The initial questionnaire for a pilot test was sent to 100 companies which were randomly selected from the 1,000 SMEs in June, 2001. The owner or manager of each company was asked to respond. Nine effective responses were collected after a follow-up mail, which represents a 9 percent response rate (excluding two wrongly-addressed questionnaires). 
After a minor modification was made to the questionnaire, the formal survey was carried out in midSeptember of 2001. Copies of the questionnaire were mailed to the owners or managers of another 900 SMEs. After the first and second follow-ups in November and December respectively, a total of 96 effective responses were received.

Because there was only a minor difference between the pilot and formal questionnaires, the pilot and formal survey responses were analysed together. Therefore, the total effective responses from 1,000 SMEs were 105. With 25 returned questionnaires because of wrong addresses, the actual effective response rate was $10.8 \%$.

Among the 105 responses, 4 are micro-companies (i.e., each of which has less than 10 employees), and 18 are large companies (i.e., each of which has more than 249 employees). This indicates that the companies' sizes may have changed since the statistics were published, or the data in the Fame Database may be inaccurate. Only 83 responses were actually from SMEs and were analysed by means of SPSS in the next section.

\section{Explanation of the response rate}

During the period of the pilot test, in order to investigate why the response rate was so low, 25 SMEs were randomly selected from the companies that did not answer the questionnaire, and their managers were telephone-interviewed. The interviews showed that the low response rate was not caused by the questionnaire, e.g., its sentences or the meaning of some terms were unclear, or hard to understand, or people feel embarrassed by answering the questions, but by the following reasons (see Table I).

(Table I is about here) 
Table I shows that most of interviewees (60\%) replied that they did not answer the questionnaire because they were too busy (44\%), or it was not directly relevant to their businesses (16\%). Other people, who are not capable or not in a position to answer the questions, will not response to the questions. The relatively low response rate may actually reflect characteristics of the target group, who appear unlikely to spend time on a questionnaire that cannot bring any direct benefits to their businesses.

Table I also shows that, the two important reasons for non-response were that: addressees had already changed jobs or retired (24\%); and the companies were bankrupt (8\%). Together they account for $32 \%$, which obviously reflected SMEs' two features: flexibility and volatility. Furthermore, $8 \%$ nonresponses were caused by the reason that questionnaires were not received. The total of these three reasons accounted for $40 \%$. This could mean that, among the target group that did not answer the questionnaire, $40 \%$ actually did not receive the questionnaire. If this factor is taken into consideration, arguably, the actual response rate in the research would be higher than the real rate.

Review of relevant literature also shows low response rates in the questionnaire surveys which were carried out in SMEs, e.g., 11\% in Ramsey et al. (2003), 10.4\% in Daniel and Wilson (2002), and 9.2\% (UK), $12.5 \%$ (Portugal) and $15.0 \%$ (Poland) in a survey carried out at the three countries (Duan et al., 2002). Saunders et al. (2003) and Hatch and Lazaraton (1991) argue that a minimum number (i.e. effective responses) for statistical analyses should be 30 . Therefore, the statistical analysis of 83 responses collected in the survey is seen as reasonable and effective, especially for a survey in the context of SMEs and KM. 


\section{Survey results and discussion}

\section{Profile of participant companies and respondents}

Figure 1 provides a profile of the companies participating in the survey. Of them $44.6 \%$ are small businesses, $25.3 \%$ medium businesses that have between 50 and 99 employees, $30.1 \%$ medium businesses that have between 100 and 249 employees.

(Figure 1 is about here)

(Figure 2 is about here)

Figure 2 shows the respondents' position in their company. $38.6 \%$ are owners or managing directors, $30.2 \%$ marketing or IT managers, $26.5 \%$ other managers, others $4.7 \%$. So, the vast majority $(95.3 \%)$ of them are senior staff.

\section{The importance of relevant knowledge for participant companies' successes}

The respondents were asked to judge the importance of adequate knowledge in the areas of "customers, competitors, suppliers, emerging market trends, own competencies/capabilities, own products/services, best practices/effective processes" to their companies' success. The result (Table II) demonstrates that knowledge in all of the listed areas is very important or important, but the order of the priority is: customers, own products/services, own competencies/capabilities, best practices/effective processes, emerging market trends, competitors and suppliers. Of the identified areas, own product/services, own competencies and capabilities, and some of the best practices/effective processes belong to internal knowledge within the company, while the others belong to external knowledge in the sectors of the task environment. Knowledge about customers is the most important for all companies. This finding strongly supports the belief that external knowledge is of prime importance to SMEs (Sparrow, 2001).

Furthermore, knowledge of competitors is perceived to be more important than of suppliers.

Knowledge of emerging market trends and some of the best practices/processes are actually related to 
customers, competitors and suppliers. Therefore, the external knowledge of customers, competitors, suppliers, emerging market trends and some best practices/effective processes are perceived as very important or important to SMEs.

(Table II is about here)

(Table III is about here)

\section{Participant companies' needs for inter-organizational knowledge transfer}

Table III indicates the participant companies' perception on the reasons for very costly errors or mistakes that they have made in the last five years. As many as $40.7 \%$ of SMEs admitted making very costly errors or mistakes because of insufficient knowledge about customers. The proportions for knowledge about suppliers, competitors and other organizations are $23.8 \%, 20.3 \%$ and $15.2 \%$ respectively. This implies that SMEs have knowledge gaps about customers, competitors, suppliers and other organizations, and thus have needs for knowledge transfer from these organizations. The main attention should be focused on the customers.

\section{Participant companies' involvement in inter-organizational knowledge transfer activities}

Table IV shows that the inter-organizational knowledge transfer activities in which more than half of SMEs are already involved are: "send employees to relevant exhibitions/congresses" (82.9\%), "use information from customers, suppliers, or other organizations to improve business performance" (75.6\%), "establish strategy to obtain information from customers, suppliers, competitors and other organizations" (61.7\%), "hire know-how from advisors or consultants" $(59.3 \%)$, and "use information from competitors to improve business performance" (58.5\%). The activities in which relatively fewer SMEs are involved are: "purchasing licenses" (17.3\%), "learning through R\&D contract" (17.9\%), "learning through joint development agreement" (23.8\%), "learning through joint ventures" (30.0\%), and "send employees to universities or research institutes for further study" (30.5\%). In total, 92.7\% of SMEs have already been involved in at least one of the inter-organizational knowledge transfer activities shown in Table IV. 
The activities in which SMEs perceive the greatest need to become involved are: "establish strategy to obtain information from customers, suppliers, competitors and other organizations" (27.2\%), "use information from competitors to improve business performance" $(20.7 \%)$, "use information from customers, suppliers, or other organizations to improve business performance" (19.5\%), and "learning through customer-supplier partnership" (17.3\%).

(Table IV is about here) 
If the companies are already involved in an activity, they may be considered as having a need for that activity. Therefore, if the categories "Yes" and "Need" are combined, SMEs have the greatest need for: "use information from customers, suppliers, or other organizations to improve business performance" (95.1\%), "send employees to relevant exhibits/congresses" (89.0\%), "establish strategy to obtain information from customers, suppliers, competitors and other organizations" (88.9\%), "use information from competitors to improve business performance" (79.2\%), "hire know-how from advisors or consultants" (64.2\%), and "learning through customer-supplier partnership" (64.2\%). Combining these results, $98.8 \%$ of SMEs either already use, or have a need for some form of interorganizational knowledge transfer.

\section{Social and electronic networks in participant companies}

Table V shows that on average, each of the SMEs belongs to 2.7 social networks. However, the standard deviation is very high, which shows that the number of networks in which SMEs are involved varies considerably.

59 respondents listed the names of the most important social networks for their companies, while 58 of them (1 missing case) assessed the effectiveness of acquiring knowledge through their most important social networks. Most of them (86.2\%) think that they are effective in acquiring knowledge through this social network. However, of these, only 32.6\% (See Table VI) have their own electronic networks.

(Table V is about here)

(Table VI is about here) 
Respondents were also asked to judge the effectiveness of electronic networks in supporting their social networks. The findings (Table VI) show that $78.6 \%$ of SMEs believed the electronic network was effective in supporting their social networks. However, it should be noted that this conclusion is based on a small sample size $(n=14)$.

Extranets are a common form of electronic network for exchanging knowledge with other companies. However, the findings (see Table VI) from the survey show relatively little use of them by SMEs. Only $19.8 \%$ of SMEs have their own extranets, while $35 \%$ can access the extranets of other companies.

Over $80 \%$ of SMEs (See Table VI) think that both social and electronic networks are important channels for them to obtain the needed knowledge. However, social networks $(88.6 \%)$ seem to be slightly preferred to electronic networks $(80.8 \%)$.

\section{Effectiveness of leveraging knowledge in participant companies}

Figure 3 shows that, only $56 \%$ of SMEs believe they are very effective or effective in leveraging knowledge from other companies to improve business performance. As shown in Table III, $36.7 \%$ of SMEs believe they made very costly errors or mistakes in the last five years because of repeating the same errors or mistakes. Taking this into consideration, it means that SMEs should improve not only their ability for successfully converting the acquired external knowledge into their own organizations, but also the ability to learn from errors or mistakes.

(Figure 3 is about here)

\section{Key findings from the survey}

Though there is no doubt over the importance of external knowledge to SMEs' success, no attempt seems to have made in the past to understand and identify SMEs inter-organisational knowledge 
transfer needs. This research intends to gain more insight into issues related to SMEs needs and their current practice using a questionnaire survey. The key findings from the survey show that:

- Adequate external knowledge in all of the areas of customers, competitors, suppliers, emerging market trends, and best practices/effective processes is perceived by respondents as very important or important to their companies' success. Of these, knowledge about customers is the most important. This finding strongly supports the argument that external knowledge is of prime importance to SMEs (Sparrow, 2001).

- Nearly half of SMEs (41\%) have made costly errors or mistakes in the last five years because of inadequate knowledge about customers, and $37 \%$ of SMEs have repeated the same errors or mistakes. Further, only $56 \%$ of SMEs believe that they are very effective or effective in leveraging knowledge from other organizations to improve their business performance. Therefore, there are large areas where SMEs can improve their abilities in acquiring adequate knowledge about their customers, and learning from their previous errors or mistakes.

- Nearly all SMEs surveyed (99\%) demonstrate a need for some forms of inter-organizational knowledge transfer, and $93 \%$ of them have already been involved in some inter-organizational knowledge transfer activities.

- Both social networks and electronic networks are considered by SMEs ( $88 \%$ and $81 \%$ respectively) to be important channels for them to acquire the needed knowledge. Most social networks are effective in helping SMEs to acquire knowledge, but only 33\% of these are supported by their own electronic networks. There is a large gap between SMEs' perception of the importance of electronic networks, and their actual use of them.

- The majority of SMEs (64\%) have been involved in, or perceive a need for, learning through customer-supplier partnership.

(Table VII is about here) 


\section{Supporting evidence from interviews}

The above findings are very positive, and strongly support the argument that external knowledge is of prime importance to SMEs (Sparrow, 2001). However, as Carr-Hill (2002) has observed, 'many of the results from a statistical analysis are simply incomprehensible without follow-up interviews with key informants'. Therefore, in order to further validate some key findings mentioned, and offer a more indepth understanding on SMEs' inter-organizational knowledge transfer needs, 12 SME managers (see Table VII), from different companies of the service sector, have been face-to-face interviewed. The interviewees were selected from the areas of Bedfordshire and London. The selection was based on the main criteria as suggested by Yin (1994): convenience, accessibility and geographic proximity.

\section{Importance of the external knowledge about customers, suppliers and competitors}

Survey findings support the research argument about the importance of external knowledge to SMEs, but they provide limited insight into issues associated with this argument and why managers believe certain types of external knowledge are more important than others. All of the 12 interviewees believe that knowledge about competitors is very important, can help them to benchmark their business practices, and effectively develop their competitive strategies. Knowledge about suppliers is also thought to be very important because the knowledge may help them to establish good relationship with the suppliers, which in turn helps them to provide better service to their customers. One manager stresses the ultimate importance of suppliers by saying that:

\footnotetext{
"When you're running a company, the most important thing is not necessarily your customer, but your supplier because if you get a right product at right price, you can sell to anybody. If you don't get a right product at right price, people will not buy it" (Interviewee8).
}

However, the other 11 interviewees still consider that customers are the most important. Good knowledge and understanding about customers is an extremely important premise for them to successfully meet their customers' needs, just as the interviewee10 has commented that:

“...if you haven’t had good understanding about your customers, have no good relationship with them, you wouldn't exist"(Interviewee10). 
Interviewee 5 even makes further comparison between the 'voices' from customers or suppliers and 'internal people and processes':

"We talk in terms of four voices in our organization and another organization: voice of customer, voice of supplier, stockholders and internal people and process. Voices of customers are obviously in terms of marketing. You need to know what the customer wants to know. You need to also understand what the customer would like to have in the short-middle term period, and predict what people we're going to meet, and what problems they like to tackle. In terms of suppliers, it is also very important. Because in some industries, the supplier shows potential trends and changes before the customer does because of their feedback chain. ... And stockholders are also important one in terms of marketing too ... Internal people and processes are not quite so much" (Interviewee5).

The above results demonstrate that the external 'voices' are more important than the internal 'voices', of them the knowledge about customer is the most important. In order to gain this kind of knowledge, good relationships with customers should be developed and maintained, so customer relationship management is worthy of being stressed in SMEs. In a word, the interview discussions with managers confirm the findings from the survey that external knowledge is of prime importance for SMEs, and help to understand why managers believe so and the importance of customer relationship management for SMEs.

\section{Involvement in inter-organizational knowledge transfer activities}

Survey results demonstrate that more than $90 \%$ of participating SMEs have been involved in interorganizational knowledge transfer activities. The interview discussions support the key findings from the survey, but more importantly, they also shed light into why and how companies have been engaged in inter-organizational knowledge transfer activities. All the interviewees admit that their companies have been extensively involved in some inter-organizational knowledge transfer activities such as regular meeting with main customers (or suppliers), getting advice from friends or counterparts in other organizations and dealing with complaints. As we know, complaints "may always happen to all companies" (Interviewee3). A specific knowledge transfer process for dealing with a complaint may be seen through the following example: 
"When some customers complain my company, the employees are asked to keep the record of the date, time, customer's name, telephone number and information about the complaint. Then, some employees will be sent to the customer, and investigate the reasons, and sort the problem out. Then, the employees are asked to report to managing director about the reasons, and knowledge about how to sort it out. MD will inform managers about the reasons that caused the complaints and experiences for dealing with them in the managers' meeting which is held once in every two weeks, the managers will inform their employees as well, make sure every employee know it, and improve our business quality" (Interviewee2).

Furthermore, some interviewees' companies have also been involved in other activities, for example, trading an innovative idea on a new type of vacuum with supplier (Interviewee1); attending technological exhibitions (Interviewees $1 \& 8$ ); conducting pilot market test with customers (Interviewees 3, 11 \& 12); using some consultancy company to do market research (Interviewee3); clarifying customers' needs (Interviewees $4 \& 5$ ); and cooperating with universities or other organizations (Interviewees 4, $6 \& 7$ ). Some companies even share knowledge with their competitors, for example:

\footnotetext{
"Sometimes, we found that some competitors are very strong in some areas, we are not so strong in these areas, we would suggest the clients use both of us, so that the clients would get better jobs. We do cooperate with some competitors. So, sometimes, I would (have) no doubt if I talk to my competitors, they share strategies with me, I share strategies with them. I would (have) no doubt (that) there are more chances for both of us to get more jobs" (Interviewee5).
}

\section{Serious mistakes or errors made because of insufficient knowledge about customers}

Though the survey reveals that nearly half of SMEs $(41 \%)$ have made costly errors or mistakes in the last five years because of inadequate knowledge about customers, it is not possible to answer why this is the case and how this could happen. The interviews conducted attempted to gain more in-depth knowledge about this issue. Of the 12 interviewees, five indicate that their companies made serious mistakes or errors in the last five years because of insufficient knowledge about customers. Three of them are consultancy companies (Interviewees 4, $5 \&$ 9), the others are a clothing shop (Interviewee6) and an international trade company (Interviewee11). The proportion $(41.7 \%)$ for the mistake-makers to the total interviewed companies is very close to the result (40.7\%) found in the survey. The reasons for the serious mistakes or errors made by the three consultancy companies are that they often find it 
very difficult to identify their customers' needs. “...what the customer thought he wanted, is not actually what he needs” (Interviewee5). “... if you say to people 'what do you want to know?' They don't know. Everybody knows what he doesn't want to know, or what he doesn't need to know. ... We have to educate the customers understand what their needs are"(Interviewee4). The clothing shop also finds it very difficult to identify the customers' true needs. “...you can get figures to show how many people shopping in certain shops, what sorts of things they are buying. But they do not always mean that your customers want that. So it is very difficult to decide what is the right way to go" (interviewee6). Furthermore, the story of the trade company demonstrates if a company doesn't have good knowledge about who is a right person to contact in a customer company, serious mistakes or errors might also occur.

"Several years ago, we began to sell a new chemical material to construction or manufacturing companies in an Asia country. After a period of time, we found that a competitor had much better performance than us although it started the business later (than us). The reason is that, it is the technical managers (of the customer companies) who decide which material should be used. We didn't know this point, and conventionally contacted the customers' salespeople, but our competitor contacted the technical managers." (Interviewee11).

\section{Importance of both social and electronic networks}

Survey results show that both social networks and electronic networks are considered by SMEs (88\% and $81 \%$ respectively) to be important channels for them to acquire the needed knowledge. Interviews with managers provide opportunities for them to elaborate their opinions on this issue. Of the 12 interviewees, two (Interviewees 6 \& 7) don't think that electronic networks are so important for them to get the needed knowledge. However, the others support this point. But only two of them (Interviewees $8 \& 12$ ) can acquire knowledge through extranets, eight mainly use the Internet to acquire knowledge because their business partners don't have or authorise them to access the extranets. More businesses are believed to be in the process of using the extranets, etc. So there is a great potential for SMEs to make further use of other electronic networks though they have benefited enormously from the Internet:

\footnotetext{
"One of the great things now is the Internet, it is fantastic for finding information. To get knowledge, one of the first things that I tend to do is to jump onto the Internet" (Interviewee9).
} 
Almost all the interviewees think that social networks are very important channels for them to acquire their needed knowledge. However, some of them (e.g., Interviewee10) admit that they are very busy and have no time to join some activities organised by some general social networks such as industrial associations or business links. They are obviously keener to join or establish the social networks that are very close to their businesses such as the networks with key customers or buying groups.

“...we (a clothing shop) are not big enough to negotiate terms. I'm a member of a buying group (a social network) so they have a lot of independent members like myself. They'll negotiate with suppliers and get better terms for us because overall getting all those retailers together we have quite good buying power. ...they are a successful group, we mainly acquire marketing information or knowledge from them" (Interviewee6).

Some interviewees (Interviewees 4, 5 \& 11) argue that some very important knowledge is more likely to get through social networks than electronic networks. For example, to address the above-mentioned serious mistakes or errors and identify the customers' true needs, a feasible solution is that the companies should establish good relationships with their customers, iteratively clarify the needs through intensive negotiation and communication. The key knowledge about the right person in interviewee11's story is also acquired through personal social network. So, interviewees seem to prefer the social networks to the electronic networks. These findings are closely correspondent to the conclusions drawn from the survey.

\section{Effectiveness of leveraging external knowledge}

The survey demonstrates that only $56 \%$ of SMEs believe that they are very effective or effective in leveraging knowledge from other organizations to improve their business performance. This issue is further explored during interviews. Half of the interviewees consider that their companies have been effective or very effective in leveraging external knowledge to improve their businesses. However the other half don't think so. This proportion (i.e., $50 \%$ ) is very close to the proportion (i.e., $56 \%$ ) found by the survey. There are various kinds of reasons for their ineffectiveness in leveraging external knowledge. For example, some companies (Interviewees 4 \& 5) don't know what they really want, so 
their knowledge gaps are very difficult to identify; key employees (Interviewee9) have no motivation to learn from business partners or key employees switch to other companies once they acquired the needed knowledge (Interviewee12); some important information or knowledge sharing between individuals are unsuccessful because of ineffectiveness in internal communication or mistakes in selecting a right communication channel (Interviewees $2 \& 5$ ). Some companies (Interviewees $5 \& 6$ ) even lack experience or ability in applying acquired knowledge into practices, here are some examples:

"Information or knowledge is there, but it is not always easy to put it into practise. ... it is very difficult to decide what is the right way to go" (interviewee6).

“... the fundamental problem with the knowledge transfer is that, knowledge transfer between some organizations and consultancy comes in the form of a huge report, so they would be presented in written form either, on paper, or on electronic format. Even if the report was given to you, you are never going to use it because it is too big, too difficult." (Interviewee5).

\section{Conclusions}

This research attempts to investigate inter-organizational knowledge transfer needs in SMEs by conducting a questionnaire survey and some company interviews. The survey offers valuable insight into the current situations of knowledge transfer in SMEs and managers' perception on various issues related to inter-organizational knowledge transfer. Key findings emerged from the survey are further validated and elaborated through the interviews. By adopting this two-tier research methodology, it is believed that the findings and results have been triangulated and strengthened, thus can provide a more reliable understanding and knowledge on SMEs' inter-organizational knowledge transfer needs and practices.

The empirical evidence from this research confirms the general belief that external knowledge is of prime importance to SMEs. The customers may have the greatest influence on SMEs, thus knowledge about the customers is perceived as most important. In order to gain this kind of knowledge, good relationships with customers should be developed and maintained, so it is evident that SMEs also need to develop and maintain good customer relationship management. 
Nearly all SMEs (99\%) demonstrate a need for some forms of inter-organizational knowledge transfer. They have extensively involved in some activities such as regular meeting with main customers (or suppliers), getting advice from friends or counterparts in other organizations, and dealing with complaints. Some of them even share knowledge with competitors. These activities are important routes for SMEs' inter-organizational knowledge transfer and their effectiveness still needs further investigations.

As nearly half of SMEs have made costly errors or mistakes because of inadequate knowledge about customers, raising awareness about this problem, identifying reasons and learning from previous mistakes need to be addressed by managers. The important reasons for causing the errors or mistakes are that the customers' true needs are very difficult to identify, and the right knowledge about doing businesses with the customers is insufficient. To address these problems, effective engagement in social networks seems to be preferable to the electronic networks.

Social and electronic networks are both important channels for SMEs to acquire the needed external knowledge. The companies are obviously keen to join or establish the social networks that are very close to their businesses such as the networks with key customers or buying groups. Most of the SMEs use the Internet to acquire knowledge, but there is greater potential for them to use other forms of electronic networks, such as online communities, Intranet, and extranets.

The empirical evidence reveals that only $56 \%$ of SMEs believe that they are very effective or effective in leveraging knowledge from other organizations to improve their business performance. Some important reasons have been identified. These includes that knowledge gaps are very difficult to identify; key employees have no motivation to learn from business partners or switch to other companies once they acquire the needed knowledge; ineffectiveness in internal communication or mistakes in selecting a right communication channel and lack of experience or ability in applying 
acquired knowledge into practices. Insights into the causes for less effective knowledge leverage in SMEs calls for more research to address this important issue.

Certain limitations of the study are recognised. Firstly, the study is based on the UK service sector, the results generated from this study may not be applicable to other industrial sectors or the same sector in other countries. Secondly, the sample selected is small and medium-sized enterprises, the results may not be applicable to micro-companies (i.e. less than 10 employees) or large companies (i.e. more than 249 employees). Thirdly, knowledge is context-based, knowledge and culture are inextricably linked in organisations (De Long and Fahey, 2000; Abou-Zeid, 2002). So, the transfer of knowledge is constrained by the cultural context in which it is embedded. Inter-organisational knowledge transfer partners suffer from their organizational and national culture differences if they are from different countries (Ford and Chan, 2003; Rodriguez et al., 2003). However, this study does not involve this cross-cultural issue. Even between organizations in the same country, the results may not apply if the national culture concerned is substantially different from that in the UK.

In addition, once SMEs have needs for inter-organizational knowledge transfer, they will carry out specific inter-organizational knowledge transfer processes to acquire the needed knowledge. However, the knowledge transfer process is very complicated, and very difficult to understand, we know little about it (Appleyard, 1996; Grant, 1996; Dyer and Nobeoka, 2000; Huber, 2001). Knowledge transfer between organizations is even more complicated than within an organization (Chen et al., 2002). Therefore, future studies are needed to develop inter-organizational knowledge transfer framework which can conceptualise the process of knowledge transfer between organizations for SMEs, help them to better understand the transfer process, and be able to address the issues of the 'boundary paradox' (Quintas et al., 1997; Beeby and Booth, 2000; Chen et al., 2002; Mohr and Sengupta, 2002). The authors of this paper are conducting explorative studies in these two areas (Chen et al., 2002; Chen et al., 2003), findings will be published in the future. 


\section{References}

Appleyard, M. M. (1996), "How Does Knowledge Flow? Interfirm Patterns in the Semiconductor Industry", Strategic Management Journal, Vol.17 (Winter Special Issue), pp.137-154.

Argyris, C. and Schon, D. A. (1996), Organizational Learning II ---- Theory, Method, and Practice, Addison - Wesley Publishing Company, ISBN 0-201-62983-6.

Barry, H. and Milner, B. (2002), "SMEs and Electronic Commerce: A Departure from the Traditional Prioritisation of Training?” Journal of European Industrial Training, Vol.26 No.7, pp. 316-326.

Beck, T., Demirguc-Kunt, A. and Levine, R. (2004) "SMEs, Growth, and Poverty: Cross-Country

Evidence" http://www.worldbank.org/research/projects/sme/Beck-SMEs_Growth_and_Poverty.pdf,

21 April, 2004 8:45 am.

Beeby, M. and Booth, C. (2000), "Networks and Inter-organizational Learning: A Critical Review", The Learning Organization, Vol.7 Issue 2.

Beijerse, R. (2000), "Knowledge Management in Small and Medium-sized Companies: Knowledge Management for Entrepreneurs", Journal of Knowledge Management, Vol.4 No.2, pp.162-179.

Bradford (2004), "SME Facts, Figures and Trends", http://www.bradford.ac.uk/smenetwork/facts.php, 1 April, 2004, 8:10pm.

Carr-Hill, R. (2002), "Homespun Patchwork Quilts", Presented at Mixed Methods Seminar: Missed Opportunities? Combining Quantitative and Qualitative Methodologies, Institute of Education.

Chase, R. L. (1997), "The Knowledge-Based Organization: An International Survey", Journal of Knowledge Management, Vol.1 No.1, pp.38-49.

Chauvel D. and Despres, C. (2002), "A Review of Survey Research in Knowledge Management: 1997 - 2001", Journal of Knowledge Management, Vol.6 No.3, pp.207-223.

Chen, S., Duan, Y. and Edwards, J. S. (2002), "Towards An Inter-organizational Knowledge Transfer Framework for SMEs", In the Proceedings of the Third European Conference on Knowledge Management (ECKM 2002), 24-25 September, Dublin, pp.160-171.

Chen, S., Duan, Y., Edwards, J. S. and Kinman, R. (2003), "Inter-organizational Knowledge Transfer Strategies for SMEs", In Edwards, J. S. (Ed.), Proceedings of Knowledge Management Aston Conference (KMAC 2003), 14-15 July, Birmingham, pp.191-204.

Daft, R., Sormunen, J. and Parks, D. (1988), "Chief Executive Scanning, Environmental Characteristics, and Company Performance: An Empirical Study", Strategic Management Journal, Vol. 9 Issue 2, pp. 123-139.

Daniel, E. and Wilson, H. (2002), "Adoption Intentions and Benefits Realised: A Study of Ecommerce in UK SMEs", Journal of Small Business and Enterprise Development, Vol.9 No.4, pp.331-348.

Davenport, T. H. and Prusak, L. (1998), Working Knowledge: How Organizations Manage What They Know, Harvard Business School Press, Boston, MA.

Deakins, D. (1999), Entrepreneurship and Small Firms, McGraw-Hill Publishing Company, England, ISBN 0077094522.

Dodgson, M. (1993), "Organizational Learning: A Review of Some Literatures", Organization Studies, Vol.14 No.3, pp.375-394.

Drucker, P. (1993), Post Capital Society, Butterworth Heinemann, London.

Duan, Y. and Kinman, R. (2000), "Small Manufacturing Businesses: Meeting Decision Support Needs", Journal of Small Business and Enterprise Development, Vol.7 No.3, pp.272-284.

Duan, Y., Mullins, R. and Hamblin, D. (2001), "Training for E-commerce Success in SMEs", In Burgess, S (Ed.), Information Technologies in SMEs: Challenges and Solutions, Idea Group Publisher.

Duan, Y., Mullins, R., Hamblin, D., Stanek, S., Sroka, H., Machado, V. and Araujo, J. (2002), "Addressing ICTs Skill Challenges in SMEs: Insights from Three Country Investigations", Journal of European Industrial Training, Vol.26 No.9, pp.430-441.

Dyer, J. H. and Nobeoka, K. (2000), "Creating and Managing a High-performance Knowledgesharing Network: the Toyota Case”, Strategic Management Journal, Vol.21, pp.345-367. 
Grandori, A. and Soda, G. (1995), "Inter-firm Networks: Antecedents, Mechanisms and Forms", Organization Studies, Vol.16 Issue 2, pp.183-214.

Grant, R. (1996), "Towards A Knowledge-based Theory of the Firm”, Strategic Management Journal, Vol.17 (special), pp.109-22.

Hatch, E. and Lazaraton, A. (1991), The Research Manual, New York: Newbury House.

Huber, G. (2001), "Transfer of Knowledge in Knowledge Management Systems: Unexplored Issues and Suggested Studies", European Journal of Information Systems, Vol.10, pp.72-79.

Ives, W., Torrey, B. and Gordon, C. (1998), "Knowledge Management: An Emerging Discipline with A Long History", Journal of Knowledge Management, Vol.1 No.4.

Johnston, K. and Loader, K. (2003), "Encouraging SME Participation in Training: Identifying Practical Approaches", Journal of European Industrial Training, Vol. 27 No.6, pp. 273-280.

Jones, O. and Beckinsale, M. (2001), "Micropolitics and Network Mapping: Innovation Management in A Mature Firm", In Jones, O., Conway, S. and Steward, F. (Ed.), Social Interaction and Organizational Change, Imperial College Press, London, ISBN 1-86094-203-2.

Lawson, R., Alcock, C., Cooper, J., and Burgess, L. (2003), "Factors Affecting Adoption of Electronic Commerce Technologies by SMEs: An Australian Study", Journal of Small Business and Enterprise Development, Vol.10 No.3, pp.265-276.

Mohr, J. J. and Sengupta, S. (2002), "Managing the Paradox of Inter-firm Learning: the Role of Governance Mechanisms", Journal of Business and Industrial Marketing, Vol.17 No.4, pp. 282301.

Nissen, M., Kamel, M. and Sengupta, K. (2000), "Integrated Analysis and Design of Knowledge Systems and Processes", Information Resources Management Journal, January - March, pp.24-43.

Preece, J. (2000), Online Communities: Designing Usability, Supporting Sociability, John Wiley \& Sons, West Sussex, England, ISBN 0-471-80599-8.

Quintas, P., Lefrere, P. and Jones, G. (1997), "Knowledge Management: A Strategic Agenda”, Long Range Planning, Vol.30 No.3, pp.385-391.

Ramsey, E., Ibbotson, P, Bell, J., and Gary, B. (2003), "E-opportunities of Service Sector SMEs: Aan Irish Cross-border Study", Journal of Small Business and Enterprise Development, Vol.10 No.3, pp.250-264.

Saunders, M., Lewis, P. and Thornhill, A. (2003), Research Methods for Business Students (Third Edition), Pearson Education Limited, ISBN 0273658042.

Sparrow, J. (2001), "Knowledge Management in Small Firms", Knowledge and Process Management, Vol.8 No.1, pp.3-16.

Szulanski, G. (2000), "The Process of Knowledge Transfer: A Diachronic Analysis of Stickiness", Organizational Behaviour and Human Decision Process, Vol.82 No.1, May, pp. 9-27.

UCE (2001), On-line Initial Self-Assessment of Knowledge Management, http://www.bs.uce.ac.uk/kmc/interactive.html, 31 January, 2001, 10:40am.

Warkentin, M., Bapna, R. and Sugumaran, V. (2001), "E-knowledge Networks for Interorganizational Collaborative E-business", Logistics Information Management, Vol.14 Issue 1/2.

Wiig, K. (1997), "Knowledge Management: An Introduction and Perspective", Journal of Knowledge Management, Vol.1 No.1.

Xu, X. M., Kaye, G. R. and Duan, Y. (2003), "UK Executives' Vision on Business Environment for Information Scanning - A Cross Industry Study", Information \& Management, Vol.40 Issue 5, pp.381-389.

Yin, R. K. (1994), Case Study Research: Design and Methods (Second Edition), Sage Publications.

USA (2002), "China's Small and Medium Enterprises: Room to Grow with WTO", http://www.useembassy-china.org.cn/econ/smes2002.html, 20 April, 2005, 2:10pm. 
Figure 1 Profile of Participant Companies

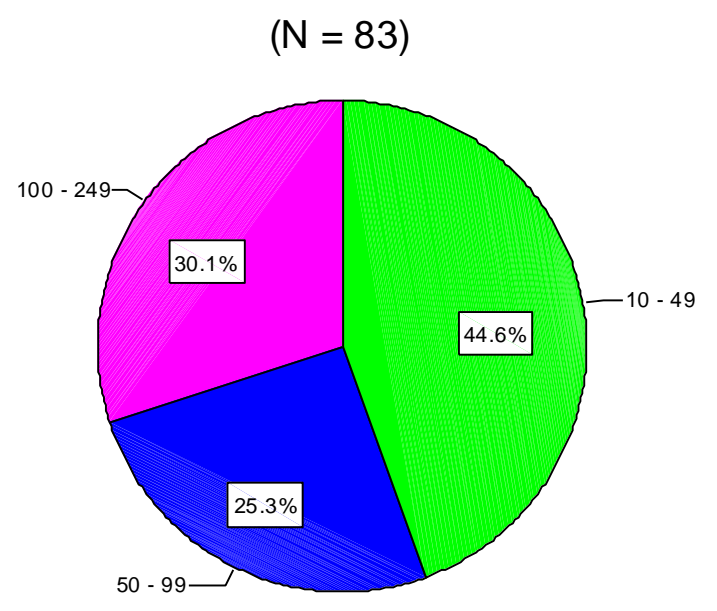


Figure 2 Profile of Respondents

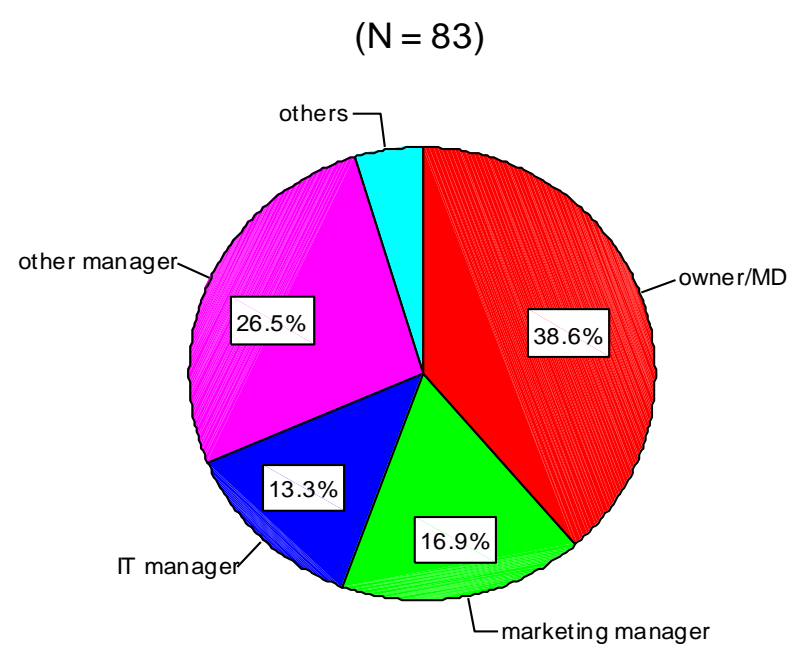


Figure 3 Effectiveness in Leveraging Knowledge

$$
(\mathrm{N}=79)
$$

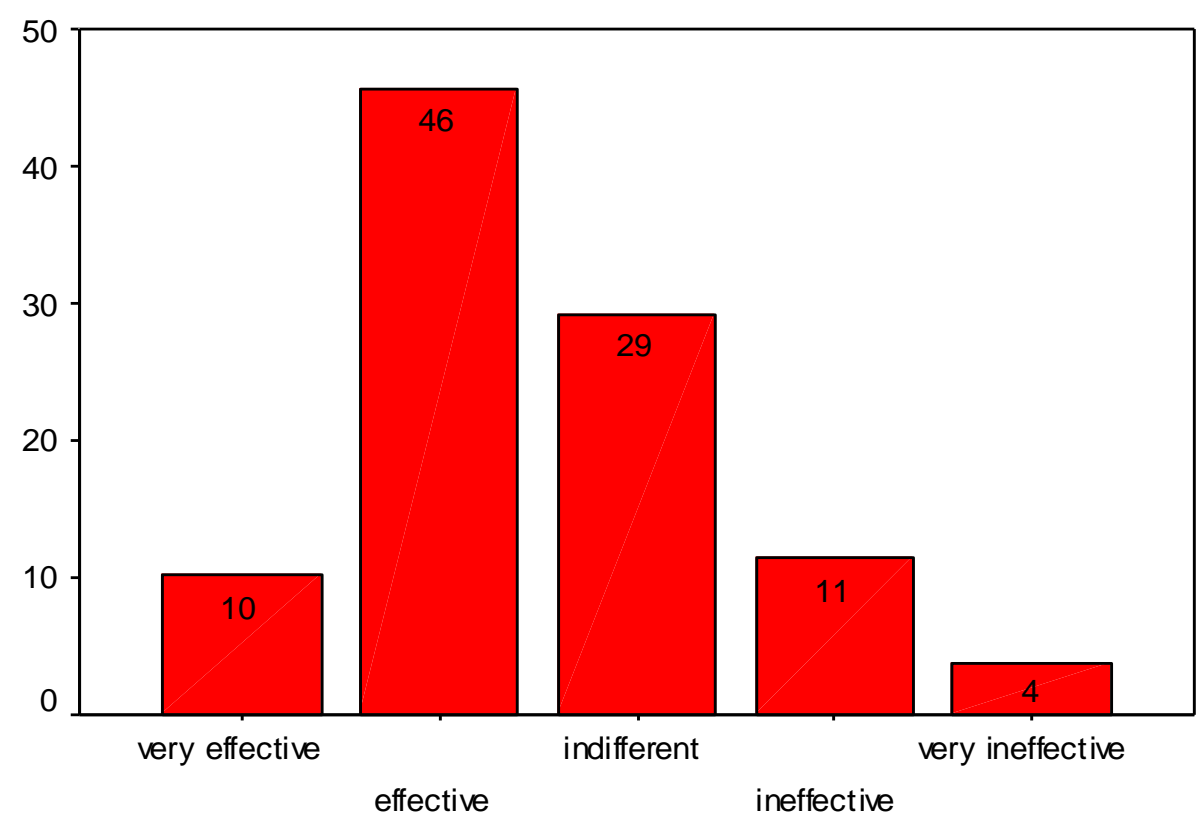


Table I Reasons and Percentages for Companies Which Did Not Answer the Questionnaire

\begin{tabular}{|l|l|l|}
\hline Reasons for not answering the questionnaire & Number of companies & Percentage (\%) \\
\hline Very busy, no time to answer the questionnaire & 11 & 44 \\
\hline It is not directly relevant to my business & 4 & 16 \\
\hline Addressee had already changed job or retired & 6 & 24 \\
\hline The company was bankrupt & 2 & 8 \\
\hline The questionnaire was not received & 2 & 8 \\
\hline Total & 25 & 100 \\
\hline
\end{tabular}


Table II Perception on the Importance of Adequate Knowledge in the Relevant Areas

\begin{tabular}{|l|l|l|l|}
\hline Relevant areas & $\begin{array}{l}\text { Type of } \\
\text { knowledge }\end{array}$ & Mean* & Std Dev. \\
\hline Customers ( $=83)$ & external & 4.84 & 0.45 \\
\hline Own product/services $(\mathrm{n}=83)$ & internal & 4.75 & 0.49 \\
\hline Own competencies and capabilities $(\mathrm{n}=83)$ & internal & 4.63 & 0.56 \\
\hline Best practices/effective processes $(\mathrm{n}=82)$ & external/internal & 4.40 & 0.56 \\
\hline Competitors $(\mathrm{n}=83)$ & external & 4.35 & 0.69 \\
\hline Emerging market trends $(\mathrm{n}=82)$ & external & 4.34 & 0.57 \\
\hline Suppliers $(\mathrm{n}=83)$ & external & 4.17 & 0.91 \\
\hline
\end{tabular}

*Note: 1 = very unimportant; 2 = unimportant; 3 = indifferent; 4 = important; 5 = very important 
Table III Types of Errors or Mistakes

\begin{tabular}{|l|l|l|}
\hline $\begin{array}{l}\text { Perception of very costly errors or mistakes for the following } \\
\text { reasons: }\end{array}$ & Yes (\%) & No (\%) \\
\hline Insufficient knowledge about customers $(\mathrm{n}=81)$ & 40.7 & 59.3 \\
\hline Repeating same errors or mistakes (n=79) & 36.7 & 63.3 \\
\hline Insufficient knowledge about suppliers (n=80) & 23.8 & 76.2 \\
\hline Insufficient knowledge about competitors (n=79) & 20.3 & 79.7 \\
\hline Insufficient knowledge about other organizations (n=79) & 15.2 & 84.8 \\
\hline
\end{tabular}


Table IV Participant Companies' Involvement in Knowledge Transfer Activities

\begin{tabular}{|c|c|c|c|c|}
\hline Relevant inter-organizational knowledge transfer activities & $\begin{array}{l}\text { Yes } \\
(\%)\end{array}$ & $\begin{array}{l}\text { Need } \\
(\%)\end{array}$ & $\begin{array}{l}\text { No- } \\
\text { need } \\
(\%)\end{array}$ & $\begin{array}{l}\text { Un- } \\
\text { known } \\
(\%)\end{array}$ \\
\hline Send employees to relevant exhibitions/congresses $(n=82)$ & 82.9 & 6.1 & 9.8 & 1.2 \\
\hline $\begin{array}{l}\text { Use information from customers, suppliers, or other organizations to } \\
\text { improve your business performance }(\mathrm{n}=82)\end{array}$ & 75.6 & 19.5 & 3.7 & 1.2 \\
\hline $\begin{array}{l}\text { Establish strategy to obtain information from customers, suppliers, } \\
\text { competitors and other organizations }(\mathrm{n}=81)\end{array}$ & 61.7 & 27.2 & 6.2 & 4.9 \\
\hline Hire know-how from advisors or consultants $(\mathrm{n}=81)$ & 59.3 & 4.9 & 28.4 & 7.4 \\
\hline $\begin{array}{l}\text { Use information from competitors to improve your business } \\
\text { performance }(\mathrm{n}=82)\end{array}$ & 58.5 & 20.7 & 12.2 & 8.5 \\
\hline Learning through customer-supplier partnership $(\mathrm{n}=81)$ & 46.9 & 17.3 & 27.2 & 8.6 \\
\hline $\begin{array}{l}\text { Send employees to universities or research institutes for further } \\
\text { study }(\mathrm{n}=82)\end{array}$ & 30.5 & 8.5 & 42.7 & 18.3 \\
\hline Learning through joint ventures $(\mathrm{n}=80)$ & 30.0 & 11.3 & 37.5 & 21.3 \\
\hline Learning through joint development agreement $(\mathrm{n}=80)$ & 23.8 & 7.5 & 46.3 & 22.5 \\
\hline Learning through $R \& D$ contract $(n=78)$ & 17.9 & 7.7 & 48.7 & 25.6 \\
\hline Purchase licence $(n=81)$ & 17.3 & 2.5 & 50.6 & 29.6 \\
\hline SMEs that answered "Yes" to Any of the above ac & \multicolumn{4}{|c|}{ 92.7\% (Responses: 76) } \\
\hline $\begin{array}{l}\text { SMEs that answered "Yes" or "Need" to Any of the above activities (n } \\
\text { 82) }\end{array}$ & \multicolumn{4}{|c|}{ 98.8\% (Responses:81) } \\
\hline
\end{tabular}


Table V The Number of Social Networks that Each of the Participant Companies Has Joined

\begin{tabular}{|l|l|l|l|}
\hline & Mean & Std Dev. & N \\
\hline The number of social networks that each of the companies has joined & 2.7 & 3.35 & 73 \\
\hline
\end{tabular}


Table VI The Participant Companies' Perceptions about Networks

\begin{tabular}{|l|l|l|}
\hline Relevant questions & $\begin{array}{l}\text { Yes } \\
(\%)\end{array}$ & $\begin{array}{l}\text { No } \\
(\%)\end{array}$ \\
\hline Does your most important social network have its own electronic network $(\mathrm{n}=43) ?$ & 32.6 & 67.4 \\
\hline $\begin{array}{l}\text { Is your most important social network effectively supported by its own electronic } \\
\text { network }(\mathrm{n}=14) \text { ? }\end{array}$ & 78.6 & 21.4 \\
\hline Does your company have its own extranet $(\mathrm{n}=81)$ ? & 19.8 & 80.2 \\
\hline Could your company access other companies' extranets $(\mathrm{n}=80)$ ? & 35.0 & 65.0 \\
\hline $\begin{array}{l}\text { Do you think social networks are important for your company to obtain the needed } \\
\text { knowledge }(\mathrm{n}=75) \text { ? }\end{array}$ & 88.0 & 12.0 \\
\hline $\begin{array}{l}\text { Do you think electronic networks are important for your company to obtain the needed } \\
\text { knowledge }(\mathrm{n}=78) \text { ? }\end{array}$ & 80.8 & 19.2 \\
\hline
\end{tabular}


Table VII General Information about the Interview Companies

\begin{tabular}{|l|l|}
\hline IntervieweeNo & \multicolumn{1}{|c|}{ Interviewee's Company Information } \\
\hline Interviewee1 & A vacuum shop, 10 employees \\
\hline Interviewee2 & Sales on teaching materials \& methods, 70 employees \\
\hline Interviewee3 & Sales on hygiene \& laundry equipment, 245 employees \\
\hline Interviewee4 & Consultancy on knowledge management, 14 employees \\
\hline Interviewee5 & Consultancy on telecommunication, 11 employees \\
\hline Interviewee6 & A clothing shop, 23 employees \\
\hline Interviewee7 & Developing trusts for communities, 37 employees \\
\hline Interviewee8 & Sales on tyres for cars, 30 employees \\
\hline Interviewee9 & Consultancy on risk management for nuclear industry, 120 employees \\
\hline Interviewee10 & Language translation service, 22 employees \\
\hline Interviewee11 & International trade on chemical materials, 10 employees \\
\hline Interviewee12 & Salvage service for insurance companies, 235 employees \\
\hline
\end{tabular}




\section{Authors:}

Shizhong Chen, Yanqing Duan, John S. Edwards and Brian Lehaney

Shizhong Chen is a doctoral student at Luton Business School, University of Luton, UK. His research interest centers on knowledge management, organizational learning, social network and e-commerce (Tel: +44(0)1582-743035; Fax: +44(0)1582-743972; E-mail: shizhong.chen@luton.ac.uk).

Yanqing Duan is a Principal Research Fellow at Luton Business School, University of Luton, UK. She earned a PhD from Aston Business School, Aston University, UK (Tel: +44 (0)1582-743134; Fax: +44(0)1582-743972; E-mail: yanqing.duan@luton.ac.uk).

John S. Edwards is a professor and a head of the Operations and Information Management Group, Aston Business School, Aston University, UK. He earned his PhD from the University of Cambridge (Tel: +44 (0)121 204 3087; Fax: +44 (0)121 204 3210; E-mail: j.s.edwards@aston.ac.uk).

Brian Lehaney is a professor and a head of the Department of Statistics and Operational Research, School of Mathematical and Information Sciences, Coventry University, UK. He earned his PhD from Brunel University, UK (Tel: + 44 (0)24 7688 8567; Fax: + 44 (0)24 7688 8270; E-mail: csx256@coventry.ac.uk). 